\title{
Cooperation with Health Professionals during the Pandemic of COVID 19
}

Ghanashyam Niraula

\begin{abstract}
The article presents light on the issues of cooperation with health workers during the COVID 19. Coronavirus pandemic has become one of the challenges to humankind and it caused devastating effects in almost all countries of the world. The purpose of the paper is to analyze how important the role of people's cooperation with health workers is during the coronavirus pandemic. The theoretical concept related to humanism and social identity theory is discussed to understand individual and group's collective effort to increase cooperation in the society during the pandemic. Subsequently, different events of cooperation among people and health workers and other incidents depicting stigma and discrimination in Nepal and other places during the COVID 19 pandemic are discussed based on a review of literatures.
\end{abstract}

Keywords: cooperation, coronavirus, health workers, pandemic, social networking

\section{Introduction}

Coronavirus disease (COVID-19) caused by the novel coronavirus was first identified in Wuhan city of China as an infectious disease at the end of December 2019. It was declared as a global pandemic on March 11, 2020, by the World Health Organization (Cennimo, 2020). Almost all countries of the world suffered from the pandemic, and Nepal could not remain untouched. People of all walks of life carried out their roles and responsibilities struggling with the COVID 19 pandemic. Among all the people, the role of health workers remained significant and most challenging because they work at the frontline to provide medical services. Professionals such as doctors, nurses, paramedics, laboratory scientists, and other health care service providers who work in health institutes or hospitals are discussed as health workers or professionals in this paper.

During the pandemic of coronavirus, public health professionals, doctors, nurses, paramedics, lab scientists as well as pharmacists are playing a very important role in providing various medical equipment and services, health care, and public awareness programs throughout the nation. In order to assist health professionals, other government bodies are also working actively to provide emergency services. In addition to the government bodies, citizens are also working together with the health workers in the battle against coronavirus. Throughout the country, they worked with the local government to make quarantines, spread awareness, and deliver daily consumed goods. In this critical time, people voluntarily assisted the local government, which supported the government and the country's health system. Good coordination among various agencies such as: local government, health service providers, police, and the federal government was observed during the pandemic in Nepal.

Health workers are members of a society and they work for the well-being of people. They provide health services; convey the right instructions, and aware the people about the pandemic. Their services, counseling, and sympathy ensure protection and make people more confident for living. These helpful and human-centered behaviors of health workers reduce fear, and panic in society (Dingwall et al., 2013). Among the members of a society, the frontline workers such as health professionals play the most vital role during the pandemic of COVID 19. Therefore, cooperation among the various members of a society will be instrumental in building a peaceful environment and return society to a fearless and safe situation.

After the eruption of coronavirus, great fear has envisaged in the mind of people. Due to a state of fear and insecurity some social perversions such as: discrimination and stigmatization were observed. For instance: coronavirus infected people were treated mercilessly and isolated from society. Likewise, it was reported that the health workers were asked to leave their rented house. However, the health workers are working day and night for the sake of people's well- being. Moreover, the people who stigmatize others also need a health professional's service when they get sick. This dual character of the people is discussed and analyzed in the paper.

In addition to this, the role of health professionals, their problems, and how the government and citizens are working with them in fighting against the pandemic is also discussed in the paper. Similarly, mutual help, understanding, and solidarity play an important role in keeping people safe in this crucial period. People need more support during crisis, emergencies, disasters, and pandemic situations than other times because people seem to be more frightened, insecure, and nervous in these 
periods of time. It could also be taken as human nature. People could share their shelter, take patients to hospitals, and provide food items and clothes to the vulnerable ones. Among them, empathy, moral support, and love is more important. Hence, in the coronavirus pandemic, solidarity and mutual help among health workers and people will make the social cohesion stronger and give strength to overcome the pandemic situation.

Next, the role of health workers is important in many ways, from providing correct information, awareness, treatment, counseling, and humanitarian service. They play a vital role to save the infected ones. That is why their importance should be realized seriously. Brown and Susskind (2020) highlighted the importance of cooperation globally during coronavirus. The writers stated that global cooperation in different forms such as developing vaccines, producing and supplying medical equipment, and sharing early information relating to pandemic among the countries will be instrumental in handling the COVID-19 situation. From the above discussion, it could be argued that in the context of Nepal cooperation among people and health workers as well as collaboration between local government and federal government is important. These sorts of cooperation will help the people to access health services easily in fighting against the coronavirus pandemic.

Indeed, encouraging and supporting the health workers will benefit the people in a pandemic because those actions will make the health workers easier to work. Ballard et al. (2020) argued that the government should increase investment in community health workers, especially in low-income countries, to fight against the pandemic as they have a strong network and help spread awareness and implement community-level measures. Similarly, the researchers claimed that the community health worker could play a lead role in contact tracing, isolating, and bringing the possible infected hospitals for testing.

In fighting against the COVID 19, the role of social networks is important. Moreover, social connections or networks play a significant role in conveying messages, showing respect, and applauding the role of health workers. Social networking is the key medium to know about any good deeds that occurred in a certain place. These sorts of good examples will have mainly two benefits. First, people will know about the good examples and try to follow them for their own benefit. Second, the actors who have done good work will feel that their work is commendable and will get encouragement in order to continue such work in the future. These examples are important in the case of health workers because the people will be directly benefitted through social networks and the active role of health workers. Similarly, acknowledging the health professionals' role during the pandemic will make them motivated to work with high morale.

The importance of health workers, their roles and problems, and why people should cooperate with them such issues are discussed in the paper. A review of journal articles, editorials, WHO guidelines, online news, and analysis of materials posted on social media was done to prepare this paper. It is clear that the pandemic situation is a crucial period of time and at the moment mutual help, understanding, and solidarity play an important role to keep people safe. Even the doctors or health professionals could be exposed to the coronavirus. Everyone could get infected despite age, sex, and income level. So, social identity theory and functionalism are also discussed in the paper to understand the importance of cooperation.

The health workers faced different problems during their work. To begin with, health workers suffer from an overload of work, they are restless and tired. Next, they also suffer from mental tension and anxiety because they also fear the possible coronavirus infection. During the pandemic period, there were incidents in Nepal that made the health workers feel sad; however, during the same time, many people collectively revered them for their great contributions. So, the different cases that the health workers faced during the pandemic are also presented in the article.

This paper aims to analyze how important the role of people's cooperation with health workers is during coronavirus pandemic. In order to meet the purpose of the research, two research questions were set. The first research question was to find the problems faced by health workers and their situation during the pandemic and the next was to know the situation and types of mutual cooperation among the public, government, and health workers to fight against coronavirus. Finally, it could be argued that working together with the health workers is not merely supporting their roles but also saving our own lives and it the responsibility of the public to support them. If we want to save our lives, dignity, and human existence, there is no option to accept and follow the rules prescribed by health professionals and work collaboratively with them during the pandemic.

\section{Methodology}

The source of information for this article was secondary and the qualitative information was analyzed. The opinions, perceptions, and analysis on the topic are subjective so the epistemology of the research was subjective in examining the reality and the research was guided by the constructivism world view. Similarly, the ontology in the research helped to know the multiple realities from different sources. While preparing the paper, internet research and some related literature were reviewed. Similarly, editorials, World Health Organization guidelines, and journal articles related to COVID 19 were reviewed. The journal articles related to coronavirus were accessed through google scholar, nature.com collections, and bmj.com hub. Furthermore, in order to understand the problems faced by the health workers and to know their opinions, some national and international online newspapers' articles were also analyzed. While reviewing the online newspapers, the situation of cooperation among public and health workers and difficulties faced by the health workers were examined. Similarly, the video posted by the international news televisions as well as by individual video makers on the Facebook was also examined to discuss the situation of health workers during the pandemic in other countries such as the USA. After watching the videos, the situation of mutual cooperation among the people and health workers, hard work of health 
workers, and people's responses during the pandemic were found. Finally, the online newspaper and videos were used in digging further about the cooperation among people health workers during the pandemic.

\section{Why is cooperation important?}

People are inside their houses but with various questions in their minds such as: will they remain safe and remain untouched by the pandemic? Will they be able to survive in case if they get infected by coronavirus? Moreover, people are worried whether the hospitals will provide health check-ups and other medical services during the pandemic if they fall sick in the meantime. This type of fear and insecurity due to the pandemic is more in a country like Nepal where there are not sufficient health facilities throughout the country. So, in this situation, there are two main responsibilities of government. The first is to ensure the citizens about the good health services available for the treatment of coronavirus infected people and the second is to mobilize the health professionals with high morale, motivation, and incentives.

In order to keep cooperation among others and feel others problem similar to own, one should understand the importance of humanism. Copson (2015) stated that a belief and commitment towards human interests is humanism and argued that the humanist put humans' interest at first and always put the human relationship at first. In my opinion, humanity and cooperation could be the best way to help the people in combating the pandemic. Kvesić et al. (2019) discussed humanism in health care as an important concept and the concept imparts that we are human beings as well as members of society. Similarly, the health professionals and patients both are human beings and both want to remain free from infections and diseases. Also, they all want to be treated as how humans want to be treated. Hence, the patients should be treated as the health professionals expect from others and the health care system should be focused on the good relationship between service providers and service receivers.

Kokudo and Sugiyama (2020) discussed the importance of cooperation and stated that pandemics do not leave people of any race, territory, and ideology and it is important to cooperate and collaborate during the difficult time and protect the lives of vulnerable ones. The researchers argued that international cooperation among the countries that played an effective role in fighting against the pandemic and cooperation did not remain limited in terms of medical supplies. The researchers further stated that the World Health Organization (WHO) also gathered virologists and experts to discuss the pandemic and different individuals and organizations also donated a large sum of money to the WHO for the treatment of infected ones.

Similarly, WHO (2020) also published an interim public health and social measures guideline to limit transmission of coronavirus and reduce morbidity and mortality from the pandemic. The guideline emphasizes not only the pharmaceutical measures but also the public health and social measures such as: hand wash, use of mask distancing, and disinfection to stop transmission at the community level. From the guideline, it could be inferred the importance of social measures in controlling the pandemic. However, in the introduction and implementation of such a guideline's cooperation among stakeholders, community engagement is needed.

In addition to this, the WHO (2020) published a feature story and discussed the stigma and attacks faced by the health care providers. The story highlighted some cases in which the patients, health workers, and health facilities have been attacked during the pandemic. Physical attack, psychological threat, use of weapons, cyber-attack, removing from home, blocking, and denial of services were some examples of attacks related to COVID-19. Along with this, some stigmas, for example: discriminatory behavior towards health care providers, patients, and the family members of the infected ones were reported during the pandemic. The story mentions that attacks on health workers not only impact the health service delivery but also add psychological stress to the patients. Although $\mathrm{WHO}$, government, and the international community have taken steps to address the stigma related to the COVID-19. Finally, I would like to argue that discrimination and allegation will not help in controlling the pandemic, instead these sorts of behaviors will obstruct the health service to the needy people. Hence, mutual understanding and cooperative behavior is needed among people and health care providers to fight against the pandemic.

The role of an individual, groups, and wider society towards health workers also matters during COVID 19. People can help health workers in many ways during the COVID 19. First, people can donate personal protective equipment to the health workers. Second, maintaining social distancing and remaining at own home is one of the ways of personal safety. Third, in order to reduce the crowd in the hospitals, it is good to visit hospitals in an emergency only. Similarly, people could provide financial assistance money to the COVID 19 fund. Lastly, expressing gratitude to the health workers over the phone will encourage the health workers. From the points mentioned above, it can be said that helping the health workers is indirectly taking care of their own and community people's health.

Similarly, Brusie (2020) suggested different ways to support nurses and health care workers to fight against coronavirus during the pandemic. She highlighted increasing the medical supplies, recognizing their hard work, managing food to the nurses, helping them with child care, delivering essentials and groceries to their houses, donating blood to the Red Cross, thanking the nurse, practicing social distancing, and calling the doctor first rather than going to the hospitals directly. From the above points, it could be inferred that all people could make a collective contribution in the fight against coronavirus from their own side.

Lau et al. (2020) argued that in the pandemic, the most vulnerable population is hit badly compared to others because vulnerable populations such as HIV infected, tuberculosis, diabetes, and patients of cardiovascular disease need more care than others. Similarly, displaced populations such as refugees often feel difficult in accessing safe living conditions, sanitation, and supply of clean drinking water, which will eventually make them fall at high risk of infection. However, arranging alternative delivery systems and extending medication services to the 
most vulnerable population can reduce their health risk during the pandemic. However, the researchers emphasized the importance of mutual partnership, communication, and trust and highlighted that mutual respect, transparency, cooperation will help to reduce stigmatization and control the pandemic.

Interestingly, functionalism could also be connected with the provision of health services. Fallon (2016) maintained that functionalism assumes that every part of society works for a purpose. For example, we can say that the health care system has a purpose to take care of good health for society's proper functioning. The author further stated that without the system of healthcare the people could not get health service. The author's argument can be elaborated as the importance of health workers in the functioning of a society. Likewise, the cooperation of people with the health workers is also essential, and unless the advice and prescription are followed by the people they cannot stay healthy and recover soon. It is so because, health professionals are the only people who have authentic knowledge, skills, and experience in health sectors. Imber (2013) also pointed out that functionalists claim mutual cooperation is essential among the different government bodies in preventing pandemic infections. From the arguments of two different authors, it could be said that mutual assistance is important among the government bodies including health institutions and health professionals with the purpose of saving the lives of people during the pandemic.

KC (2020) argued the role of health workers in a very sensitive way and claimed that health workers are one of the important components of the health system and without them, the health system cannot function. He asserted that when health workers are ill from other diseases, they could perform their responsibilities and render their services. But he questioned, "Can they continue their services when they are infected with coronavirus"? Of course no. The writer pointed out that when health professionals get infected with coronavirus, they should either take leave or remain in quarantine. He further questioned, "What will happen if there are very few health professionals to provide health services"? If the whole team of a health facility is infected, then the services will automatically be halted. So, it could be imagined how important health workers' role is. One very important thing everyone should realize is health workers' services are very important to protect other lives.

The importance of cooperation could also be looked at from a theoretical lens. Suttie (2020) discusses with Atkins, Paul co-author of Prosocial about the role of common interests and cooperation to stop spreading or overcoming the coronavirus pandemic. The co-author talks about cooperation and group behavior and argues that if all of the people worldwide come together, it will be easier to control coronavirus. He provides an example if people give more importance to self-interest, it will not protect groups' interest. He substantiated his arguments by saying that the personal interest of going to coffee shop may become cause of spreading the virus. Likewise, the accumulation of essential supplies for personal benefit may be the reason behind the scarcity of supplies. He also discussed eight different principles such as: social identity, ensuring other needs are met, making decisions collectively, being open and transparent, reward and punishment systems that help to work together.

The researcher discussed social identity theory and claimed that sharing in groups means cooperating with others. When people share something that they have with the people who do not have during the pandemic, it could be said that they will develop a sense of cooperation. Furthermore, the researcher claimed that Asian countries did a better job in comparison to the US in controlling coronavirus due to the collective feeling. He compared the Asian countries with the Western countries and argued that the countries that believed in collectiveness rather than individualism did better control the spreading of coronavirus by completely following lockdown. He substantiated his arguments, saying complete lockdown is an example of working together for groups and collective effort to stop spreading the coronavirus.

Generally, people used to claim that the medical sector is one of the most profit-making businesses in Nepal. People argue doctors working either in private or government hospitals pay more attention to make income rather than service. However, in the pandemic situation, people have praised the roles of doctors and other health workers in Nepal. If we see the opinions of health workers of Nepal and other countries, they are all committed and working for the assistance of others which could be considered as a great example of selfless service.

Some health professionals shared opinions about their jobs during the pandemic of COVID 19 in the United States through video in YouTube. The doctors opined that they feel like frontline soldiers fighting against the enemy and they are putting the diagnosis of coronavirus at the top of every patient. In the same video, they also shared they still worked even they did not have enough Personal Protective Equipment (PPE). One of the doctors said that they felt very bad when they had to return the patients when there was no availability of test (The Guardian, 2020). Likewise, the case was similar in Nepal, in the initial phase when there were few cases of coronavirus the health workers had no PPE, surgical gloves, and masks however they continued their services. From this, it could be imagined how important the role of health workers is and their role is the best protective measures for saving human lives.

Likewise, the cooperation among the family members inside a house also assist health workers in their work. An example which can be illustrated by a video posted on social media is discussed below. In a family, the mother was a nurse and she had adult daughters. The video was amazing which showed mutual respect, sympathy, and deep cooperation with a mother nurse by her two daughters. The nurse was worried due to the absence of essential medical supplies in her hospital. She sadly expressed that she was not scared of the coronavirus but was worried whether she would not be able to see her daughters. She said that in the absence of new masks at the hospitals there is more chance of being infected with the virus. She further said that when she gets infected, she should remain at the hospitals and she would not be able to see her daughters. The nurse's voice made her daughter frustrated. The daughters stitch cloth-made masks and prepared spaghetti for her mother 
and her colleagues (Dhar, 2020). The video portrays that the three women had a strong sense of cooperation because they want to remain safe and live longer. Finally, it could be claimed that one of the best ways to beat the coronavirus is working together.

Shrestha (2020) shared her own experience in one of the Nepali online news "Setopati.com" which is presented as follows. She was a staff nurse originally from Nepal who works in a hospital near London, UK. She is a survivor of coronavirus. She said that she used to work 12 hours a day and spend 10-15 min with each coronavirus patient in a hospital. There were 20 patients of coronavirus in the hospital where she used to work. She got infected and the infection was also transmitted to her son and husband by her. However, she remained in isolation at her own home. After two weeks of complete isolation, she gradually started getting relief and joined her job after some weeks' rest. She shared her feelings very interestingly and said that she was quite nervous and scared when she started to go to the hospital after her recovery. However, she felt that whether a soldier will be afraid of joining the war? She compared herself with the soldiers in the war and started working with much confidence as before. She further elaborated on her experiences in the United Kingdom (UK) during the pandemic and shared when people fnd the nurses standing in a queue in supermarkets to buy groceries, people revered them and requested not to stand in a queue waiting for their turn. She further added that some people of the city also came with a lunch box in the hospitals to feed the nurses. With such responses of the people, she said that she felt adored being a nurse.

From the above story of a nurse, it can be learned that the people in the health profession are rendering services keeping their own health at risk for humankind. Therefore, it could be argued that it is a prime duty of all the citizens to join hands together with the health professionals to fight against coronavirus. The health workers could be supported in many ways. First, in this crucial time, they need encouragement, support, and sympathy from the people as well as the government. Second, they should be supported at their houses by families. They could also be given more privilege in public places such as shops, supermarkets, and transportation. When we are supporting them, we are eventually working for our own protection.

Health workers have similar types of challenges throughout the world. Not only in Nepal but in many countries of the world the condition of health workers is very busy and hectic. They are overwhelmed with their duties much more than before the outburst of a pandemic. This could be evidenced by a news article published in the $\mathrm{BBC}$ online. In the news, there was a photo of a nurse named Elena, who was fallen asleep in her table after her whole night duty. She was a nurse in a hospital in Italy. The nurse expressed that she was tired due to the long hours of work. While caring for the patients of coronavirus, she also got infected. She said that she was proud of her work and added that although the photo was hers but it also represented the situation of all nurses and doctors (Natarajan et al., 2020). It could be argued that the health workers around different parts of the world are working for the public and cooperation could be an essential virtue to fight against the coronavirus.

\section{Discussion}

Certainly, COVID 19 has remained a big fear in the mind of people and health workers as well as the people who have been affected by the pandemic. Due to the lack of facts and ignorance, people fail to follow and also neglect the information provided by the health workers. Likewise, being only concentrated on self-interests, it is seen that they do not care about others. As a result, health workers were tortured, discriminated and mishandled. In addition to this, the coronavirus infected people have fallen in discrimination and some are tortured by the landlords which is also discussed in the above section. Finally, torture and harassment will definitely decrease motivation among the health professionals and which ultimately matters the service delivery.

On the contrary, it was also reported that many people in Kathmandu observed a program of lighting candles and clapping hands to show respect, solidarity and encourage the frontline workers such as doctors, health professionals, and security personnel for their selfless services and hard work. Moreover, the Nepal government has also announced some additional benefits in addition to their monthly salary for the encouragement of the health workers. Finally, it is surprising to know about different thoughts and behaviors of Nepali people at the same time.

Lastly, from the two cases presented above, as a sociology and development student, I have a question and dilemma in my mind that why Nepali people have different thoughts and opinions. Why don't we show mutual respect, cooperation, and understanding to fight against our common problem? What has created differences and tension in our Nepali society? And we also need to find out how we could move together to keep our society safe and harmonious in this crisis. I think this should be an issue of discussion at present time and believe that social scientists have a great role to find out misunderstandings and create cooperation among the people to fight against the coronavirus pandemic.

It could be discussed the above cases from a theoretical perspective also. Skinner's reinforcement theory tells that appreciation, trophy and grades are the positive reinforcement that will encourage continuing the reward behavior(McLeod, 2018). Importantly, health professionals are the main persons who help to save the lives during these sorts of crisis and it is our duty to cooperate with the health professionals in order to save our own lives.

Although, we cannot completely deny that there were no discouraging incidents for the health workers during the pandemic. However, people immediately denounced the discouraging acts and conveyed message that cooperation should be kept intact and supporting health professionals is a prime responsibility. For example: once a case of mistreatment of a doctor by a patient's relative came out, some influencers who work in diverse sectors of Nepal came up with a short video message to show solidarity and respect towards the health workers. They further appealed everybody to respect the doctors and get united to fight against coronavirus (COVID 19, 2020). Hence from the 
case discussed above, it can be argued that in the pandemic situation, there is more need for mutual cooperation between the public and the health workers to make the health service functioning effectively.

George et al. (2017) conducted qualitative research to find the motivating and demotivating factors for community health workers in India and concluded that lack of recognition, rude behavior, and inadequate remuneration were some of the demotivating factors for community health workers. If we examine the cases of mishandling and discriminating against the health workers, we can infer that the cases are the demotivating factors for health workers. Certainly, those types of behaviors will discourage the health workers to work at their duty stations, and finally, people will get suffered.

Cooperation with health workers is important to the people for their own benefits. If we think from a functionalism perspective, it tells that every unit of a society serves with a purpose. Health workers serve a society through health services and society cannot function without health workers. They are part of a society like an organ in a body. Hence, it is the responsibility of people to help and cooperate with them in the pandemic situation for their own survival. Similarly, if we look from the social identity perspective, health workers and other groups are two different groups by profession however, they are all members of a society. The stigma and discrimination may certainly hurt the health workers. But, on the other hand, support and cooperation will encourage them in their work. Likewise, from the humanism perspective, we can say that the interest of humans is very important than other things and it should be kept at first. To sum up, discussing the three perspectives, it could be claimed that health workers and other people all are a part of a society both need support and cooperation which will ultimately enhance the effort to fight against the COVID 19 pandemic.

At last, the scientists around the world are working to develop a vaccine against coronavirus and the news has been reporting that they are very near to get success in it. In the future, if the vaccine will be going to be used among the larger population throughout the world then the role of health workers will be prominent. That's why cooperation with the health workers to fight against the COVID 19 is essential and important.

\section{Conclusion}

Before the pandemic, the role of health institutes was sometimes criticized in Nepal as a profit-making institute, however, in the pandemic, health workers even worked in the absence of medical service sets such as PPE and surgical gloves for saving peoples' lives. It means that health workers put public health at high priority during a difficult time. This is an example of their deep respect and cooperation with people from the health workers' side.

Similarly, some good examples of cooperation with the health workers from the people side were visible through some inspirational online videos posted on social media. Likewise, health workers themselves share the best example of cooperation from the public side towards them. Moreover, Nepal Government's decision to provide extra benefits to the health workers also enhanced the motivation of health workers to perform their responsibilities. Finally, cooperating with the health workers is not that we are supporting in their roles but also saving our own lives and it also our responsibility.

Overall, after reviewing different materials available through secondary sources, it is found that except for a few reported cases, people highly appreciated the role of health workers and cooperated with them during the pandemic in Nepal. People also recognized their roles and valued their hard work.

To sum up, health workers are working for humankind and their role is crucial. Respecting, assisting them, and following their advice and precaution are some forms of cooperation. Certainly, cooperation with the health workers will be a source of motivation for them to work. On the other hand, torture, harassment, and neglecting precautions and advice during the pandemic will also discourage them. Lastly, during the pandemic, a strong sense of cooperation among the health workers and people is essential which was observed during the pandemic of coronavirus. It is also necessary to continue working together in order to beat the coronavirus is together.

\section{Acknowledgments:}

I would like to thank Dr. Suresh Gautam, Assistant Professor, Kathmandu University School of Education for providing useful suggestions while preparing this article. I also thank the anonymous reviewers for their insightful comments after carefully reading the manuscript.

\section{Funding:}

The author received no funding for this research

\section{Ethical approval for the research:}

Not applicable

\section{Consent for Publication:}

Not applicable

\section{Conflict of interest:}

The author does not have any conflict of interest with respect to this research

Ethical Conduct of Research: Not applicable

\section{References}

Ballard, M., Bancroft, E., Nesbit, J., Johnson, A., Holeman, I., Foth, J., Rogers, D., Yang, J., Nardella, J., Olsen, H., Raghavan, M., Panjabi, R., Alban, R., Malaba. S., Christiansen, M., Rapp, S., Schechter, J., Aylward, P., Rogers, A., \& Palazuelos, D. (2020). Prioritising the role of community health workers in the COVID-19 response. BMJ Global Health Journal, 5(6), 2-6. http:// dx.doi.org/10.1136/bmjgh-2020-002550

Brown, G., \& Susskind, D. (2020). International cooperation during the COVID-19 pandemic. Oxford Review of Economic Policy, 36(S1), S64-S76. https:// doi.org/10.1093/oxrep/graa025 
Brusie, C. (2020, March 20). 20 Ways to support nurses $\&$ healthcare workers on the front lines of COVID-19. Blog. Retrieved from https://nurse.org/articles/20ways-to-support-healthcare-workers/

Cennimo, D. J. (2020, November 25). How did the coronavirus outbreak start? Medscape. Retrieved from https://www.medscape.com/ answers/2500114-197402/how-did-the-coronavirusoutbreak-start

COVID-19. (2020, June 7). Nepali influencers come together in solidarity with health workers [Video]. Retrieved from YouTube. https://www.youtube.com/ watch? $\mathrm{v}=44 \mathrm{Z5bViPRs}$

Copson, A. (2015). What is Humanism? In Copson, A. \& Grayling, A.C. (Eds),_The Wiley Blackwell Handbook of humanism (pp. 1 -34). Wiley Blackwell. https://onlinelibrary.wiley.com/doi/ pdf/10.1002/9781118793305

Dingwall, R., Hoffman, L. M., \& Staniland, K. (2013). Introduction: why a Sociology of Pandemics? Sociology of Health \& Illness, 35(2).167-173. https:// onlinelibrary.wiley.com/doi/pdf/10.1111/14679566.12019

Dhar, M. (2020, May 30). Nurse can't see her children due to covid, what her daughters do will shock you [Video]. Retrieved from Facebook.https://www.facebook.com/ dharmannofficial/videos/1932397083564113

Fallon, S. (2016, March 22). Functionalism $\mid$ sociology | Chegg Tutors [Video].Youtube. https://www.youtube. com/watch? $\mathrm{v}=\mathrm{JSmaNnU} 3 \mathrm{uAI}$

George, M. S., Pant, S., Devasenapathy, N., Jerath, S.-G. \& Zodpey, S. P. (2017). Motivating and demotivating factors for community health workers: A qualitative study in urban slums of Delhi, India. WHO SouthEast Journal of Public Health, 6(1), 82-89. https://doi. 10.4103/2224-3151.206170

Imber, M. F. (2013, May 21).Functional cooperation in the United Nations. Encyclopaedia Britannica. Retrieved from https:/www.britannica.com/topic/functionalisminternational-organizations

KC, B. B. (2020, April 18). COVID 19 and safety of health workers. SetopatiNepal's DigitalNewspaper.Retrieved from http://ratopati.com/story/126668/2020/4/18/ covid-and-health-workers-safety

Kokudo, N., \& Sugiyama, H. (2020). Call for international cooperation and collaboration to effectively tackle the COVID-19 pandemic. Global Health \& Medicine, 2(2), 60-62. https://doi.org/10.35772/ghm.2020.01019

Kvesić, A., Galić, K., \& Vukojević, M. (2019). Humanism influencing the organization of the health care system and the ethics of medical relations in the society of Bosnia-Herzegovina. Philosophy, Ethics, and Humanities in Medicine, 14(12). https://doi. org/10.1186/s13010-019-0082-7

Lau, L. S., Samari, G., Moresky, R. T., Casey, S. E., Kachur. S. P., Roberts, L. F. \& Zard. M. (2020). COVID-19 in humanitarian settings and lessons learned from past epidemics. Nature Medicine, 26, 647-648. https://doi. org/10.1038/s41591-020-0851-2

McLeod, S. (2018). Skinner- operant conditioning. Simply Psychology. $\quad$ https://www.simplypsychology.org/ operant-conditioning.html

Natarajan, S., Lowen, M., \& Parkinson, C. (2020, May 12). Coronavirus: Four nurses on four continents tell their story. $B B C$ News. Retrieved from https://www. bbc.com/news/in-pictures-52616933

Shrestha, U. (2020, May 13). Returned to work after overcoming coronavirus. Setopati Nepal's Digital Newspaper. Retrieved from https://www.setopati. com/opinion/206139

Suttie, J. (2020, April 1). How can we cooperate when the pndemic is driving us apart? Greater Good Magazine. Retrieved from https:/greatergood.berkeley.edu/ article/item/how can_we_cooperate_when the pandemic is driving us apart

The Guardian. (2020, March 21), US health workers on the coronavirus frontline [Video]. Retrieved from YouTube. https://www.youtube.com/watch? $v=G K y r e Y 0 R Z p U$

World Health Organization [WHO]. (2020, July 30). Attacks on health care in the context of COVID-19. Feature Stories. Retrieved from https://www.who.int/ news-room/feature-stories/detail/attacks-on-healthcare-in-the-context-of-covid-19

World Health Organization [WHO]. (2020, November 4). Considerations for implementing and adjusting public health and social measures in the context of COVID-19. Interim Guidance. Publications. Retrieved from file:///C:/Users/Dell/Downloads/WHO-2019nCoV-Adjusting PH measures-2020.2-eng.pdf

Ghanashyam Niroula, https://orcid.org/0000-00023628-9075 is M. A. in Population Studies from Tribhuvan University and M. Sc in Social Research Methods from the University of Teesside UK. At present, he is pursuing M. Phil degree in Development Studies at School of Education, Kathmandu University. Currently, he is associated with Kathmandu University High school. Niroula's publications are focused on social and demographic issues of Nepali society.

Email: nir.ghanashyam@gmail.com 